\title{
Sugar-free Workplace: A Step for Fighting Obesity
}

Jaafar Sahned $^{1}$, Dereen Mohammed Saeed ${ }^{2}$, Subhasis Misra ${ }^{1}$

1. Surgery, Brandon Regional Hospital, Brandon, USA 2. Pathology, University of Illinois, Chicago, USA

Corresponding author: Jaafar Sahned, sahned.jaafar@hcahealthcare.com

\section{Abstract}

Currently, there is a worldwide obesity pandemic with an incidence that has increased progressively over the last few decades. Obesity is considered a global health hazard and is associated with a significant economic impact on the healthcare system. It has been linked to several serious medical conditions, including heart disease, hypertension, stroke, diabetes mellitus, and cancer. Obesity is also related to social and psychological problems such as anxiety and depression. Several factors predispose the population to obesity, including decreased physical activity and non-healthy dietary habits. Sugar is the most important key contributor to the pandemic of obesity, and implementing a sugar-free workplace policy will provide a promising strategy for fighting obesity.

Categories: Public Health

Keywords: sugar free, sugar, obesity, pandemic

\section{Introduction And Background}

Obesity is regarded as a global health problem (Figures 1,2), and it has surpassed malnutrition in both prevalence and related deaths. There is presently a worldwide pandemic of obesity-a change from being an epidemic health problem primarily in high-income countries. The prevalence of obesity has tripled over the last four decades, with an estimated 13\% of the world's adult population being obese in 2016 and almost 40\% being overweight. While obesity prevalence is increasing in adults, there has been a more dramatic increase in pediatric populations, with the prevalence increasing by 4.5 times since 1975, and more than 380 million children being overweight or obese in 2016 [1].

Received 11/26/2019

Review began 12/05/2019 Review ended 12/07/2019 Published 12/10/2019

\section{๑) Copyright 2019}

Sahned et al. This is an open access article distributed under the terms of the Creative Commons Attribution License CC-BY 3.0., which permits unrestricted use, distribution, and reproduction in any medium, provided the original author and source are credited.

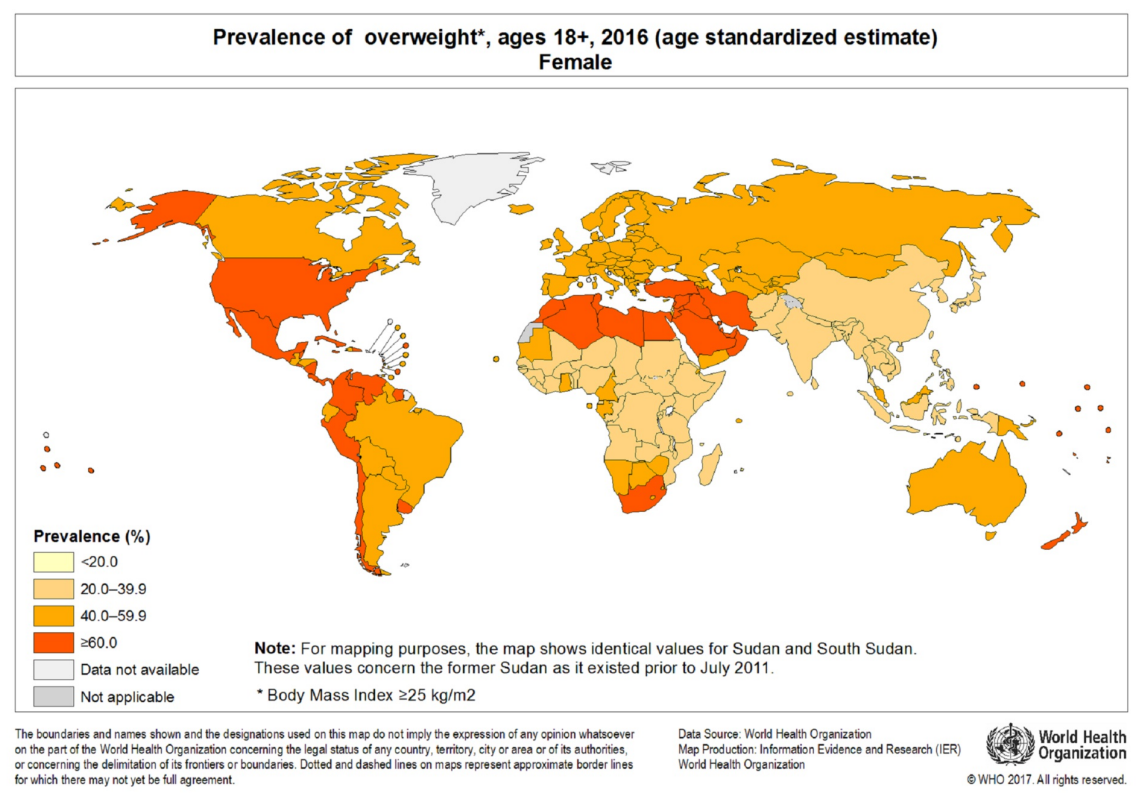

FIGURE 1: WHO world map of prevalence of overweight in adult female. 


\section{Cureus}

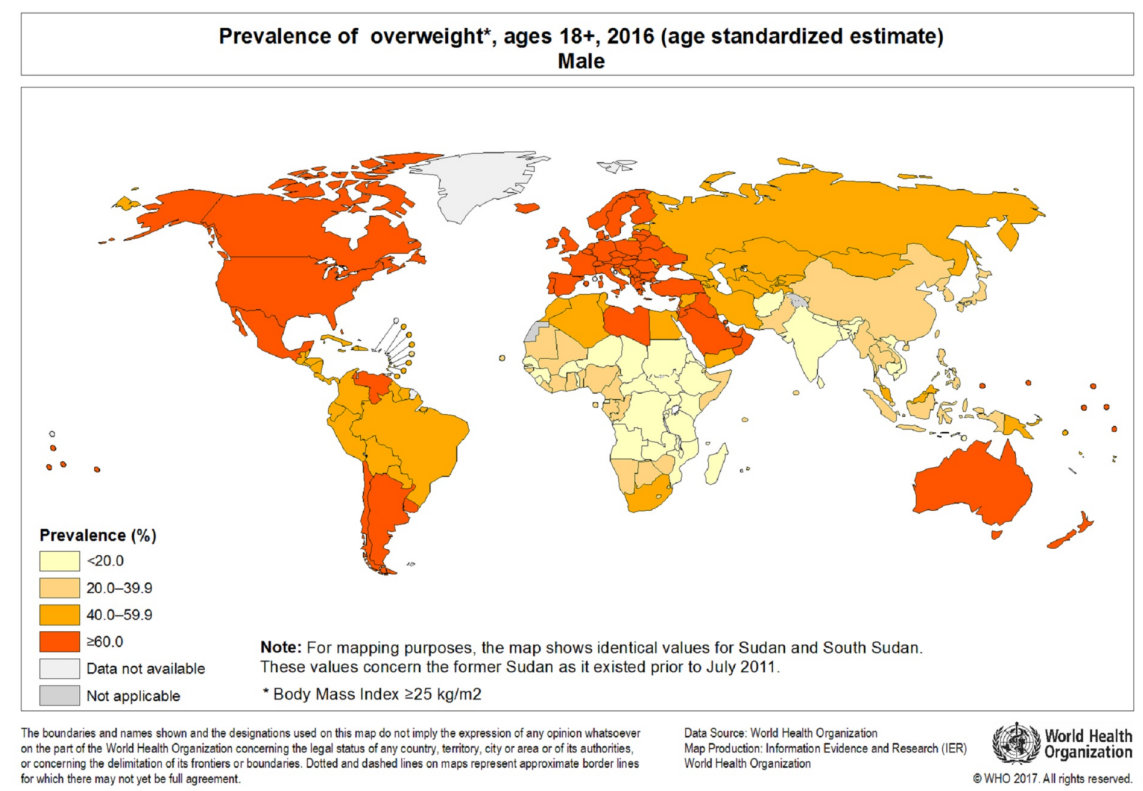

FIGURE 2: WHO world map of prevalence of overweight in adult male.

Obesity in the United States is a much more common health problem than any other health issue, with a prevalence of about $40 \%$ [2]. It is estimated that the annual cost of obesity was $\$ 147$ billion in 2008 [2]. Global obesity contributed to four million deaths and 120 million disability-adjusted life years (DALYs). Obesity-related mortality rate increased by $28 \%$ from 41.9 per 100,000 in 1990 to 53.7 per 100,000 in 2015. Similarly, obesity-related DALYs increased by $35.8 \%$ from 1,200 per 100,000 in 1990 to 1,630 per 100,000 in 2015 [3]. An increase in the prevalence of obesity is attributed to the increased consumption of added sugars. It is estimated that more than $55 \%$ of people in the United States consumes over 50 grams added sugar daily (Figure 3), which is considered more than the advised maximum daily intake according to American Heart Association. World Health Organization (WHO) recent guideline recommends adults and children reduce their daily intake of free sugars to less than $10 \%$ of their total energy intake. A further reduction to below $5 \%$ or roughly 25 grams (six teaspoons) per day would provide additional health benefits [4].

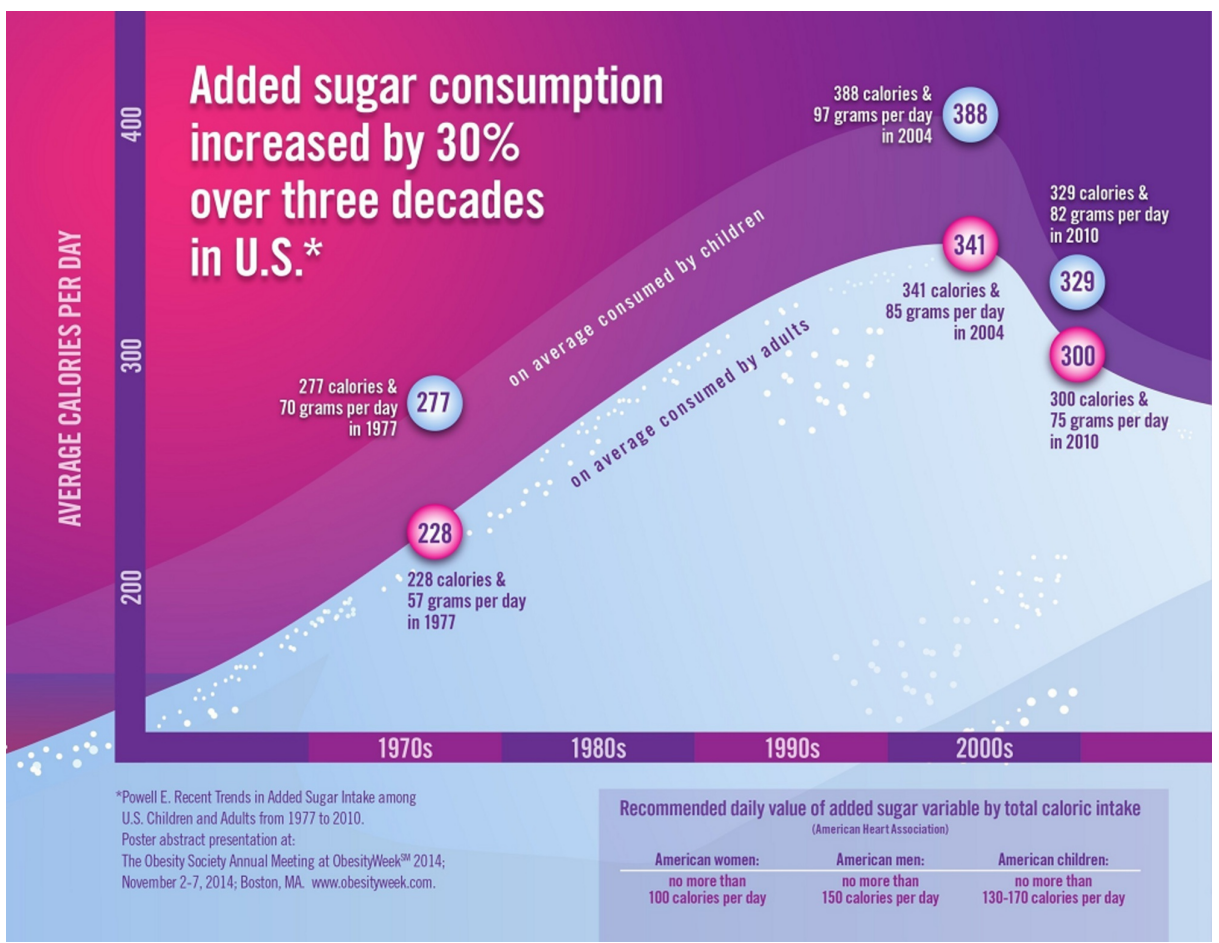

FIGURE 3: Added sugar consumption in the United States from 1977 to 2010. 


\section{Review}

Dietary factors are considered to be the major drivers for obesity. Increased availability and easy access to unhealthy food contribute to the global obesity. Total energy intake increased over the last five decades for all income groups. From 1965 to 2008, the total energy intake increased by 634, 462, and $492 \mathrm{KJ} /$ day in low, middle, and high socioeconomic groups, respectively [5]. Increased energy consumption was attributed to the increased frequency of eating away from home foods. It is estimated that home consumed diet decreased by $23 \%$ from 1965 to 2008 [5]. National Center for Health Statistics in 2013 published data on consumption of added sugar between 2005 and 2010 in the United States with approximately 14\% of young adults' total caloric intakes obtained from added sugars during this period [6].

The key targets for any obesity control policy are the food and physical activity environments. However, reduced physical activities are considered as potential factors for global obesity but are less likely to be major contributors since urbanization with subsequent decline in the physical activities preceded the obesity pandemic [4]. Different interventions are usually suggested by healthcare providers to promote increased physical activity and a healthy diet. Unfortunately, nearly half of patients are not very engaged or not engaged at all in addressing their obesity [7]. It is of critical importance to implement people-based strategies for the prevention of obesity that target factors at both personal and environmental levels. These strategies aim to alter physical activity environments to facilitate higher levels of physical activities and to reduce sedentary lifestyles. Additionally, they provide healthier food choices through different food policies (e.g., nutritional labeling, formulation, restricting unhealthy food, and providing healthier choices at lower prices). It has been shown that reducing the price by half on healthier food items will increase their purchase by $93 \%[8]$.

\section{Food landscape}

The "food landscape" represent what, when, where, and how the food is presented. Easy access and availability of unhealthy food with intense food marketing and advertisement are the two major factors contributing to unhealthy dietary habits with subsequent weight gain. Resolving this crisis may require focusing on both individual behavior and food environments that serve as barriers to nutritional behavior change. While individual measures are not always effective in controlling obesity, improving food environments and marketing serve as barriers to unhealthy nutritional behavior.

\section{The rationale}

Workplaces play a critical role in raising awareness of obesity and an unhealthy diet and can make a greater impact on the community's eating habits; therefore, implementing a policy or intervention to reduce obesity in the workplace setting is an ideal situation. Unfortunately, the prevalence of obesity among healthcare workers is very concerning, with no significant difference in the prevalence of obesity between nurses and people working in non-healthcare-related jobs. At the same time, obesity among healthcare professionals has a negative impact on a personal level and may negatively promote obesity [9]. Evidence for reducing weight is promising for worksite programs; however, the effects on other cardiometabolic risk factors are inconsistent [10]. For any obesity control intervention to be effective, it should be a policy and not just a promotional effort. The best example of this is seen in the results of the Step Ahead trial, a randomized controlled trial involving six hospitals in Massachusetts [11]. The trial combined ecologic interventions to prevent weight gain of hospital employees with strategies to promote physical activity (e.g., stairway signs, outdoor walking routes) and healthy eating, as well as campaigns and challenges for weight loss, physical activity, and healthy eating. No significant differences in body mass index at one- and two-year follow-ups were demonstrated [11]. Participation in this trial was low, and likely there was no consistent adherence to all interventions, which could be attributed to the level of medical knowledge and education of the participants. Hospitals, like other workplaces, have a high prevalence of obesity.

\section{Policy implication}

Sugar-sweetened drinks and diet may be key contributors to the epidemic of obesity [12]. These drinks and food provide high sugar with low satiety [12]. A systematic review and meta-analysis of 30 trials and 38 prospective cohort studies showed a significant association between sugar and obesity in adults [13]. Another systematic review and meta-analysis of 22 prospective cohort studies and randomized controlled trials provides evidence that consumption of sugar-sweetened beverages (SSB) is associated with weight gain in children and adults [14]. SSB consumption is also associated with increased incidence of diabetes mellitus (DM) [15], metabolic syndrome [16], hypertension [17], coronary heart disease [18,19], stroke [20], and gout [21]. School-based interventions demonstrate a lower incidence of obesity among students with limited soft drink consumption [12]. It has been shown that replacing soft drinks with healthier choices in vending machines could actually increase sales while significantly reducing calorie intake per drink purchased [22]. Many hospitals across the country implement the sugar-free hospital policy. Participating hospitals include Baylor Health Care System (Dallas, Texas), Cleveland Clinic Foundation (Cleveland, Ohio), Indiana University Health (Indianapolis, Indiana), Children’s Mercy Hospital (Kansas City, Missouri), Seattle Children's Hospital (Seattle, Washington), University of Michigan Health System (Ann Arbor, Michigan), and 


\section{Health and economic impact}

Reducing sugar consumption likely will have a major positive impact at both the health and economic levels. Consumption of supraphysiological dosage of sugar has been associated with increased risk for coronary artery disease [24], hyperlipidemia [25,26], hypertension [27-29], DM [30-32], non-alcoholic fatty liver disease $[33,34]$, and cancer $[35,36]$. Vreman et al. estimated that a $20 \%$ reduction in added sugars intake will effectively reduce the prevalence of coronary artery disease, DM, fatty liver, and obesity [37]. The Diabetes Remission Clinical Trial (DiRECT), a recent randomized controlled trial on type 2 DM, demonstrated that using intensive weight management and restricted diet program will cause remission of type 2 DM in almost half of the patients. A mean weight loss of $10 \mathrm{~kg}$ with more than $15 \mathrm{~kg}$ weight loss in $24 \%$ after one year of intervention was reported [38]. The economic benefits are mainly obtained by reducing the cost of metabolic disease and obesity-related health problems. A simulated open cohort study is being conducted from 2015 to 2035 , with a base cohort of more than 22,000 patients with new people entering the model each year at age 20 [37]. The study aims to demonstrate that an estimated reduction of $20 \%$ of sugar will reduce annual direct medical costs for US adults by more than $\$ 10$ billion by the year 2035 , while a $50 \%$ reduction will save $\$ 21$ billion. In addition, health outcomes will significantly improve with $20 \%$ reduction of sugar consumption by averting about 770,000 DALYs, while 50\% reduction in consumption will avert another 1.6 million DALYs [37].

\section{Limitations}

Energy imbalance is a major determinant of the potential for dietary sugars to influence weight changes. Sugar consumption should not be the sole determinant of a healthy diet since there are many other dietary factors contributing to obesity like consumption of excess calories and high fat diet. It would be a difficult goal to legislate and modify individual's eating behavior which both may play major roles in limiting the implementation of a dietary policy.

\section{Conclusions}

It is important to identify the determinants of the surge in national and global obesity rates and to implement sugar-free policy interventions in the workplace to control the pandemic of obesity and metabolic syndrome. Workplace cafeterias, cafes, vending machines, and gift shops should offer healthy meals with more fruits, vegetables, and low-fat diet and sugar-free drinks.

\section{Additional Information \\ Disclosures}

Conflicts of interest: In compliance with the ICMJE uniform disclosure form, all authors declare the following: Payment/services info: All authors have declared that no financial support was received from any organization for the submitted work. Financial relationships: All authors have declared that they have no financial relationships at present or within the previous three years with any organizations that might have an interest in the submitted work. Other relationships: All authors have declared that there are no other relationships or activities that could appear to have influenced the submitted work.

\section{References}

1. Obesity and overweight. (2018). Accessed: June 1, 2019: http://www.who.int/news-room/factsheets/detail/obesity-and-overweight.

2. Adult obesity facts. (2018). Accessed: June 9, 2019: https://www.cdc.gov/obesity/data/adult.html.

3. GBD 2015 Obesity Collaborators, Afshin A, Forouzanfar MH, et al.: Health effects of overweight and obesity in 195 countries over 25 years. N Engl J Med. 2017, 377:13-27. 10.1056/NEJMoa1614362

4. WHO calls on countries to reduce sugars intake among adults and children . (2015). Accessed: November 28, 2019: https://www.who.int/mediacentre/news/releases/2015/sugar-guideline/en/.

5. Smith LP, Ng SW, Popkin BM: Trends in US home food preparation and consumption: analysis of national nutrition surveys and time use studies from 1965-1966 to 2007-2008. Nutr J. 2013, 12:45. 10.1186/14752891-12-45

6. Ervin RB, Ogden CL: Consumption of added sugars among U.S. adults, 2005-2010. NCHS Data Brief. 2013, 122:1-8.

7. Volpp KG, Mohta NS: Patient engagement survey: the failure of obesity efforts and the collective nature of solutions. NEJM Catal. 2018,

8. Chan RS, Woo J: Prevention of overweight and obesity: how effective is the current public health approach . Int J Environ Res Public Health. 2010, 7:765-783. 10.3390/ijerph7030765

9. Thorndike AN: Workplace interventions to reduce obesity and cardiometabolic risk . Curr Cardiovasc Risk Rep. 2011, 5:79-85. 10.1007/s12170-010-0138-0

10. Lemon SC, Zapka J, Li W, et al.: Step ahead: a worksite obesity prevention trial among hospital employees . Am J Prev Med. 2010, 38:27-38. 10.1016/j.amepre.2009.08.028

11. Kyle RG, Wills J, Mahoney C, Hoyle L, Kelly M, Atherton IM: Obesity prevalence among healthcare professionals in England: a cross-sectional study using the Health Survey for England. BMJ Open. 2017, 7:018498. 10.1136/bmjopen-2017-018498

12. Malik VS, Schulze MB, Hu FB: Intake of sugar-sweetened beverages and weight gain: a systematic review . 
Am J Clin Nutr. 2006, 84:274-288. 10.1093/ajcn/84.1.274

13. Te Morenga L, Mallard S, Mann J: Dietary sugars and body weight: systematic review and meta-analyses of randomised controlled trials and cohort studies. BMJ. 2013, 346:7492. 10.1136/bmj.e7492

14. Malik VS, Pan A, Willett WC, Hu FB: Sugar-sweetened beverages and weight gain in children and adults: a systematic review and meta-analysis. Am J Clin Nutr. 2013, 98:1084-1102. 10.3945/ajcn.113.058362

15. Imamura F, O'Connor L, Ye Z, et al.: Consumption of sugar sweetened beverages, artificially sweetened beverages, and fruit juice and incidence of type 2 diabetes: systematic review, meta-analysis, and estimation of population attributable fraction. BMJ. 2015, 351:h3576. 10.1136/bmj.h3576

16. Malik VS, Popkin BM, Bray GA, et al.: Sugar-sweetened beverages and risk of metabolic syndrome and type 2 diabetes: a meta-analysis. Diabetes Care. 2010, 33:2477-2483. 10.2337/dc10-1079

17. Jayalath VH, de Souza RJ, Ha V, et al.: Sugar-sweetened beverage consumption and incident hypertension: a systematic review and meta-analysis of prospective cohorts. Am J Clin Nutr. 2015, 102:914-921. 10.3945/ajcn.115.107243

18. de Koning L, Malik VS, Kellogg MD, Rimm EB, Willett WC, Hu FB: Sweetened beverage consumption, incident coronary heart disease, and biomarkers of risk in men. Circulation. 2012, 125:1735-1741. 10.1161/CIRCULATIONAHA.111.067017

19. Huang C, Huang J, Tian Y, Yang X, Gu D: Sugar sweetened beverages consumption and risk of coronary heart disease: a meta-analysis of prospective studies. Atherosclerosis. 2014, 234:11-16. 10.1016/j.atherosclerosis.2014.01.037

20. Bernstein AM, de Koning L, Flint AJ, Rexrode KM, Willett WC: Soda consumption and the risk of stroke in men and women. Am J Clin Nutr. 2012, 95:1190-1199. 10.3945/ajcn.111.030205

21. Choi HK, Willett W, Curhan G: Fructose-rich beverages and risk of gout in women . JAMA. 2010, 304:22702278. 10.1001/jama.2010.1638

22. Hospital vending machines: helping people make healthier choices. (2018). Accessed: November 25, 2019: https://publichealthmatters.blog.gov.uk/2018/07/20/hospital-vending-machines-helping-people-makehealthier-choices/.

23. Examples of hospitals with healthy food and beverage policies . (2018). Accessed: June 10, 2019: https://cspinet.org/resource/examples-hospitals-healthy-food-and-beverage-policies.

24. Bray GA: Fructose and risk of cardiometabolic disease . Curr Atheroscler. 2012, 14:570-578. 10.1007/s11883012-0276-6

25. Marckmann P: Dietary treatment of thrombogenic disorders related to the metabolic syndrome . Br J Nutr. 2000, 83:S121-S126. 10.1017/S0007114500001057

26. Bray GA, Popkin BM: Calorie-sweetened beverages and fructose: what have we learned 10 years later . Pediatr Obes. 2013, 8:242-248. 10.1111/j.2047-6310.2013.00171

27. DiNicolantonio JJ, Lucan SC: The wrong white crystals: not salt but sugar as aetiological in hypertension and cardiometabolic disease. Open Heart. 2014, 1:000167. 10.1136/openhrt-2014-000167

28. Feig D, Soletsky B, Johnson R: Effect of allopurinol on blood pressure of adolescents with newly diagnosed essential hypertension. J Am Med Assoc. 2008, 300:924-932. 10.1001/jama.300.8.924

29. Nguyen S, Choi HK, Lustig RH, Hsu CY: Sugar-sweetened beverages, serum uric acid, and blood pressure in adolescents. J Pediatr. 2009, 154:807-813. 10.1016/j.jpeds.2009.01.015

30. DiNicolantonio JJ, O’Keefe JH, Lucan SC: Added fructose: a principal driver of type 2 diabetes mellitus and its consequences. Mayo Clin Proc. 2015, 90:372-381. 10.1016/j.mayocp.2014.12.019

31. Basu S, Yoffe P, Hills N, Lustig RH: The relationship of sugar to population-level diabetes prevalence: an econometric analysis of repeated cross-sectional data. PLoS One. 2013, 8:e57873. 10.1371/journal.pone.0057873

32. Goran MI, Ulijaszek SJ, Ventura EE: High fructose corn syrup and diabetes prevalence: a global perspective . Glob Public Health. 2013, 8:55-64. 10.1080/17441692.2012.736257

33. Clark JM: The epidemiology of nonalcoholic fatty liver disease in adults . J Clin Gastroenterol. 2006, 40:S5S10. 10.1097/1001.mcg.0000168638.0000184840.ff

34. McCullough A: Update on nonalcoholic fatty liver disease . J Clin Gastroenterol. 2002, 34:255-262. 10.1097/00004836-200203000-00013

35. Cantley LC: Cancer, metabolism, fructose, artificial sweeteners, and going cold turkey on sugar . BMC Biol. 2014, 12:8. 10.1186/1741-7007-12-8

36. Bartrina JA, Rodrigo CP: Association between sucrose intake and cancer: a review of the evidence . Nutr Hosp. 2013, 4:95-105. 10.3305/nh.2013.28.sup4.6802

37. Vreman RA, Goodell AJ, Rodriguez LA, Porco TC, Lustig RH, Kahn JG: Health and economic benefits of reducing sugar intake in the USA, including effects via non-alcoholic fatty liver disease: a microsimulation model. BMJ Open. 2017, 7:e013543. 10.1136/bmjopen-2016-013543

38. Lean ME, Leslie WS, Barnes AC, et al.: Primary care-led weight management for remission of type 2 diabetes (DiRECT): an open-label, cluster-randomised trial. Lancet. 2018, 391:541-551. 10.1016/S01406736(17)33102-1 